\title{
THE RESULTS OF A COMPARISON OF A BRAZILIAN AND AN IMPORTED KNEE PROSTHESIS - 5 YEARS OF FOLLOW-UP
}

\author{
OS RESULTADOS DE UMA COMPARAÇÃO DE UMA PRÓTESE \\ DE JOELHO BRASILEIRA E UMA IMPORTADA - \\ CINCO ANOS DE ACOMPANHAMENTO
}

\author{
Joao Henrique Costa Calegari ${ }^{1}$ (D), Thiago Cavalcante Coelho Marqueze ${ }^{1}$ (1), Omar Sharid Teixeira El Kadri ${ }^{1}$ (i), \\ Eike Jefferson Galdino Pereira ${ }^{2}$ (1), Alexandre Oliveira Queiroz ${ }^{3}$ (1), Paulo Roberto Bignardi $I^{2}$ (1),

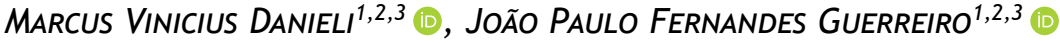 \\ 1. Hospital Evangélico de Londrina, PR, Brazil. \\ 2. Pontifícia Universidade Católica do Paraná (PUCPR), Faculdade de Medicina, Campus Londrina, PR, Brazil. \\ 3. Hospital de Ortopedia UNIORT.E, Londrina, PR, Brazil.
}

\section{ABSTRACT}

Introduction: To compare the functional results, satisfaction rates, and revisions of total knee arthroplasties performed by the same surgical team using either Brazilian or imported implants, with a minimum follow-up of 5 years after surgery. Materials and Methods: A retrospective cohort study analyzing the medical records and interviews of patients who underwent total knee arthroplasty with Brazilian or imported implants with a minimum of 5 years after surgery. Results: One hundred and fifty patients were evaluated (164 knees). In the functional questionnaire, $71 \%$ of patients had favorable answers in the group of patients who underwent surgery using the Brazilian prosthesis and $74.8 \%$ in the group with imported implants $(p=0.634)$. There was no statistical difference in satisfaction between the groups, with $78.4 \%$ of patients satisfied or very satisfied in the Brazilian implant group and $90.7 \%$ in the imported implant group ( $p=0.053)$. Loosening of the implants was reported in $5.3 \%$ versus $4.7 \%$ ( $p>0.999)$. Conclusion: The total knee arthroplasties performed by the same surgical team with a minimum follow-up period of 5 years showed similar levels of satisfaction, function, and complications with both the Brazilian and imported implants. Level of Evidence III, cohort study.

Keywords: Arthroplasty. Replacement. Knee. Knee prosthesis.

\section{RESUMO}

Introdução: Comparar resultados funcionais, índices de satisfação e revisões de artroplastias totais de joelho realizadas pela mesma equipe cirúrgica usando implantes brasileiros ou importados, com acompanhamento mínimo de cinco anos após a cirurgia. Material e Método: Estudo de coorte retrospectivo com análise de prontuários e entrevistas de pacientes submetidos à artroplastia total do joelho com implantes brasileiros e importados com no mínimo cinco anos de pós-operatório. Resultados: Foram avaliados 150 pacientes (164 joelhos). No questionário funcional, encontramos $71 \%$ dos pacientes com respostas favoráveis no grupo de pacientes submetidos à cirurgia com uso de próteses brasileiras e 74,8\% no grupo com implantes importados $(p=0,634)$. Em relação à satisfação, não houve diferença estatística entre os grupos com $78,4 \%$ dos pacientes satisfeitos ou muito satisfeitos no grupo com implante brasileiro e 90,7\% no grupo com implante importado $(p=0,053)$. A ocorrência de soltura dos implantes foi relatada em 5,3\% versus 4,7\% ( $p>0,999)$. Conclusões: As artroplastias totais de joelho realizadas pela mesma equipe cirúrgica com acompanhamento mínimo de cinco anos apresentaram níveis semelhantes de satisfação, função e complicações com os implantes brasileiros e importados. Nível de evidência III, estudo de coorte.

Descritores: Artroplastia. Substituição. Joelho. Prótese de joelho.

Citation: Calegari JHC, Marqueze TCC, Kadri OSTE, Pereira EJG, Queiroz AO, Bignardi PR, Danieli MV, Guerreiro JPF. The results of a comparison of a brazilian and an imported knee prosthesis - 5 years of follow-up. Acta Ortop Bras. [online]. 2022;30(1): Page 1 of 3. Available from URL: http://www.scielo.br/aob.

\section{INTRODUCTION}

Degenerative osteoarthritis affects $4 \%$ of the Brazilian population 1 . The best solution found to treat advanced knee osteoarthrosis is total arthroplasty and, in developed countries, the increase in arthroplasties already produces relevant social and economic impacts ${ }^{1}$. A large proportion of total knee arthroplasties in our country is performed with imported implants which, thanks to the exchange rate discrepancy, transportation, taxes and import costs, can cost twice the price of the material manufactured in Brazil². Imported implants are widely used abroad, many cases are monitored and have durability rates that reach up to $82 \%$ in 25 years $^{3}$. Some Brazilian implants have shown good durability in biomechanical

All authors declare no potential conflict of interest related to this article.

The study was conducted at the Hospital de Ortopedia Uniort.e and the Hospital Evangélico de Londrina.

Correspondence: João Paulo Fernandes Guerreiro, Av. Higienópolis, 2.600, Londrina, PR, Brazil, 86050170. drjoaopauloguerreiro@gmail.com 
tests ${ }^{4}$, but we do not have large clinical studies with a long follow-up period proving the same durability and results. Some national case series have already demonstrated good results and low revision rate with some Brazilian implants in a medium-term follow-up ${ }^{5-6}$. The choice of implant impacts health care costs and generates a lot of conflicts between surgeons and health managers ${ }^{7-8}$

Our objective was to evaluate whether there are differences in functional results, satisfaction rates and revisions between Brazilian and imported implants used by the same surgical team and with a minimum follow-up of 5 years after surgery.

Our hypothesis was that there is no difference in satisfaction, function, and revision rates between imported and Brazilian implants used by the same surgical team with a minimum follow-up time of 5 years.

\section{MATERIALS AND METHODS}

A retrospective cohort study was carried out with analysis of medical records of 377 patients who underwent total knee arthroplasty using Brazilian and imported implants. All patients were operated on by the same team, which included three knee surgeons, between 2010 and 2015. The data collection took place between August 2020 and June 2021 after approval by the Research Ethics Committee. The preoperative inclusion criteria were patients with primary osteoarthritis, Ahlbäck classification ${ }^{9}$ of arthrosis type 3, 4 and 5 . The postoperative inclusion criteria were a minimum follow-up of 5 years and complete medical records. The preoperative exclusion criteria were valgus deformity, osteoarthritis secondary to inflammatory diseases and fracture sequelae. The postoperative exclusion criteria were patellar replacement, use of an implant with preservation of the posterior cruciate ligament, the impossibility of phone contact for interview and patients who did not agree to participate in the phone interview after reading the informed consent form.

The selected cases were subdivided into two groups: "national" when undergoing surgery with the Brazilian implant $(\mathrm{MB} \AA$, Meta Bio Ltd., Rio Claro, São Paulo, Brazil) and "imported" when undergoing with the imported implant (NexGen ${ }^{\circ}$, Zimmer, Warsaw, IN, USA). The two models of prosthesis used have a similar design (Figure 1) and compatible surgical instruments. The choice of the type of implant for each patient was based on the option of the surgeon, the patient, and the health plan at the time of surgery. In medical records, we searchisd for the following information: name, gender, date of birth, date, of surgery, type of implant used and whether the patient underwent a new surgery (arthrofibrosis release, cleaning without exchan!ye material, osteosynthesis due to

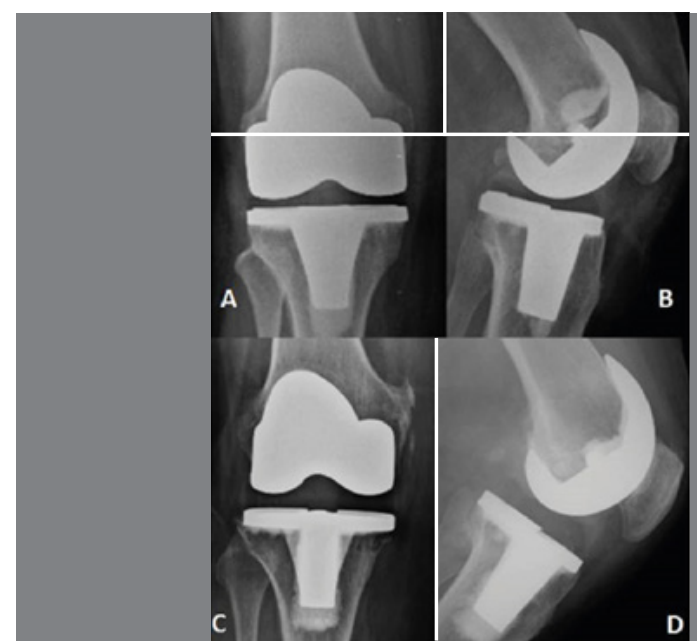

Figure 1. A and B: Brazilian Implant; C and D: Imported Implant. peri-prosthesis fracture or revision surgery), if the patient underwent revision surgery, what was the cause (stiffness, infection, aseptic loosening, peri-prosthetic fracture or anterior pain requiring patellar replacement). In the interview with the patient, we searched for new information about treatments or the need for new surgeries not reported in the medical record and asked about the degree of satisfaction with the procedure (very dissatisfied, a little dissatisfied, a little satisfied, satisfied or very satisfied), if he would underwent the surgery again (if yes or no), and if there were symptoms at that moment related to the operated knee (yes or no), what symptoms were present: any difficulty to walk (yes or no), if he could support his body weight on the operated leg (yes or no), if he had any difficulty using stairs (yes or no), any difficulty to squat (yes or no), the presence of knee swelling (yes or no), if he could bend the knee to 90 degrees of flexion (yes or no), if he felt any disturb such as crackles or "noise" when moving the knee (yes or no).

For the analysis of qualitative variables, the Chi-square test or Fisher's Exact test was used. For quantitative variables, the ShapiroWilk test was first applied to verify normality, then the Mann-Whitney test was used for non-normal data and test for variables with Gaussian distribution. The results were analyzed using the Statistical Package for Social Sciences program (SPSS Inc., Chicago, IL, USA) - 18.0, with a confidence level of $5 \%$ being established for all applied tests.

\section{RESULTS}

We selected 125 patients (143 knees) that met the inclusion and exclusion criteria. There were 57 patients in national group and 86 in the imported group. The two groups matched in age, sex, and follow up (Table 1).

Regarding the answers to the functional questionnaire that we created, we found $71 \%$ of patients with favorable responses in the group of patients submitted to the Brazilian prosthesis and $74.8 \%$ in the group with imported implants, with no statistical difference between the groups (Figure 2). Regarding satisfaction, there was also no statistical difference between the groups with $78.4 \%$ of satisfied or very satisfied patients in the group with Brazilian implants and $90.7 \%$ in the group of patients with imported prosthesis (Figure 3). Evaluating new surgeries, aseptic loosening and other causes, we found similar rates between the implants (Table 2).

\begin{tabular}{|c|c|c|c|}
\hline & National & Imported & P Value \\
\hline Age (years) & $76,1 \pm 6.5$ & $74,8 \pm 7,7$ & 0.294 \\
\hline Gender (F/M) & $43 / 14$ & $67 / 21$ & 0.698 \\
\hline Follow-up (years) & $6,85(5,2-9,64)^{*}$ & $6,56(5,18-9,96)^{*}$ & 0.292 \\
\hline
\end{tabular}

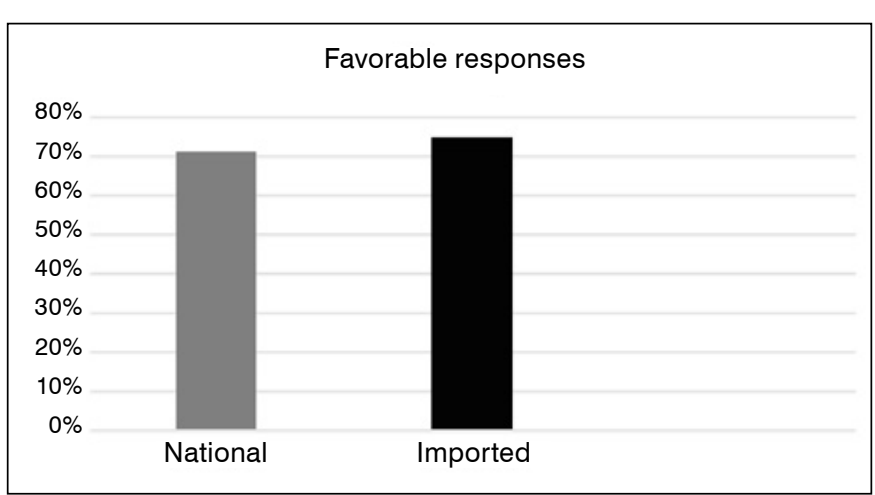

Figure 2. Function Questionnaire $(p=0.634)$. 


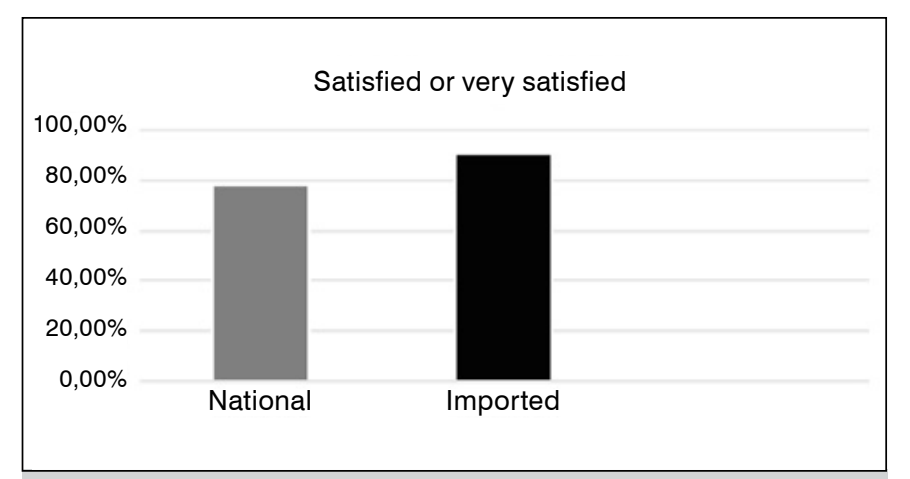

Figure 3. Satisfaction Index $(p=0.053)$.

\begin{tabular}{|c|c|c|c|}
\hline & National & Imported & P Value \\
\hline New surgery & $11 / 57(19,3 \%)$ & $12 / 86(14,0 \%)$ & 0.725 \\
\hline Infection & $3 / 57(5,3 \%)$ & $4 / 86(4,7 \%)$ & $>0,999$ \\
\hline Aseptic loosening & $3 / 57(5,3 \%)$ & $4 / 86(4,7 \%)$ & $>0,999$ \\
\hline Arthrofibrosis & $2 / 57(3,5 \%)$ & $2 / 86(2,3 \%)$ & $>0,999$ \\
\hline Fracture & $0 / 57(0 \%)$ & $1 / 86(1,2 \%)$ & $>0,999$ \\
\hline Haematoma & $3 / 57(5,3 \%)$ & $1 / 86(1,2 \%)$ & 0,301 \\
\hline
\end{tabular}

\section{DISCUSSION}

This study shows that, in a medium-term follow up, the results of surgeries with Brazilian and imported implants performed by the same medical team had statistically similar results regarding satisfaction rate, functional results and complications.

Our results of satisfaction and functional questionnaire were comparable to the national and international literature and regardless the type of implant used ${ }^{5-6,10-12}$. Kahlenberg et al. ${ }^{12}$ shows, in a retrospective cohort, similar results of improvement in function and satisfaction among 4069 patients undergoing five of the most common different international brands of implant.

Aseptic loosening rate in this study was $4.8 \%$ in the evaluated patients. In a literature review, Labek et al. ${ }^{13}$ found a $12 \%$ rate of revisions in 10 years in the largest international series. We found good results regarding aseptic loosening in two case series with Brazilian implants with a mean follow-up of 5 years ${ }^{5-6}$ and in another national case series that used the imported implant ${ }^{10}$ with similar follow-up. Barreto et al. ${ }^{5}$ presents in his series 58 knees and no revision due to aseptic loosening. He reports only 3 cases of asymptomatic patients with radiolucents on radiographs. Vasconcelos et al. ${ }^{6}$ presents the results of $53 \mathrm{knees}$ and does not report loosening or revisions. Fuchs et al. ${ }^{10}$ with imported implants presents 68 knees and 2 cases $(2,9 \%)$ of aseptic loosening. One case with loosening due to wear of the patellar component and another case in a patient with rheumatoid arthritis. This study has several limitations. First, the mean follow-up time was 6.6 years, while we predict a durability of more than 15 years in most cases. Second, the number of patients is limited for a retrospective cohort on this topic. Third, we didn't do any objective functional tests on the patients, just a simplified questionnaire about function, so the patient could understand and answer on the phone. This can make it difficult to compare our results with other studies. Due to the fact that we evaluated a population of patients from the same center and operated by the same team, we believe there was an advantage in making these comparison. We know that the implant is just one of the factors that lead to a successful procedure ${ }^{7-8}$. There are several other factors that hinder the analysis of the results of arthroplasties in our country, such as: the heterogeneous characteristics of the services that perform arthroplasties; the lack of documentation of results; the low adherence of patients to long-term follow-ups (especially in cases with good results); cultural, structural, and socioeconomic issues that limits the access to medical services ${ }^{1,14}$. Our study showed, as well as the few previous case series using Brazilian implants ${ }^{5-6}$ that the Brazilian implant has results comparable to the imported. A better investment in registries and in follow-up of patients using these implants can lead to an increase in the reliability of the Brazilian implant. This can contribute to cost reduction and economic improvement for our healthcare system.

\section{CONCLUSION}

Total knee arthroplasty performed by the same surgical team in a minimum follow-up period of 5 years showed similar levels of satisfaction, function, and complications between the Brazilian and imported implants used.

AUTHORS' CONTRIBUTION: Each author contributed individually and significantly to the development of this article. JHCC: drafted the article, sought volunteers and analyzed the data; TCCM: drafted the article, sought volunteers and analyzed the data; OSTEK: drafted the article, sought volunteers and analyzed the data, EJGP: drafted the article, sought volunteers and analyzed the data, AOQ: reviewed the article and contributed to the intellectual concept of the study; PRB: performed statistical analysis and reviewed the article; MVD: reviewed the article and contributed to the intellectual concept of the study; JPFG: drafted and reviewed the article, performed statistical analysis and contributed to the intellectual concept of the study and the entire research project.

\section{REFERENCES}

1. Ferreira MC, Oliveira JCP, Zidan FF, Franciozi CEDS, Luzo MVM, Abdalla RJ. Total knee and hip arthroplasty: the reality of assistance in Brazilian public health care. Rev Bras Ortop. 2018. 8;53(4):432-440.

2. Bittencourt C. HC de São Paulo cria prótese de joelho mais barata que as importadas. Folha de São Paulo. [Internet]. Set 2014. [acesso em junho 2021]. Disponivel em: https://www.unasus.gov.br/noticia/ hc-de-sao-paulo-cria-protese-de-joelho-mais-barata-que-importadas.

3. Evans JT, Walker RW, Evans JP, Blom AW, Sayers A, Whitehouse MR. How long does a knee replacement last? A systematic review and meta-analysis of case series and national registry reports with more than 15 years of follow-up. Lancet. 2019. 16;393(10172):655-63.

4. Pécora JR, Romero V. Evaluation of Polyethylene Wear in a Brazilian Ultracongruent Knee Prosthesis with a Rotating Platform. Rev Bras Ortop (Sao Paulo). 2021.56(1):42-46.

5. Barretto JM, Malta M, E Albuquerque RP, de Assis DP, Campos AS. Medium-term assessment of total knee arthroplasty with implant made in brazil. Rev Bras Ortop. 2015.6;46(5):540-5.

6. Vasconcelos JW, Leite LMDS, Sousa JCA, Sousa JOM, Santos E Santos MF Medium-term evaluation of total knee arthroplasty without patellar replacement. Rev Bras Ortop. 2013. 13;48(3):251-56.

7. Healy WL, lorio R. Implant selection and cost for total joint arthroplasty: conflict between surgeons and hospitals. Clin Orthop Relat Res. 2007.457:57-63
8. Kahlenberg CA, Lyman S, Joseph AD, Chiu YF, Padgett DE. Comparison of patient-reported outcomes based on implant brand in total knee arthroplasty: a prospective cohort study. Bone Joint J. 2019. 101-B(7_Supple_C):48-54

9. Ahlbäck S. Osteoarthrosis of the knee. A radiographic investigation. Acta Radiol Diagn (Stockh). 1968:Suppl 277:7-72. PMID: 5706059.

10. Fuchs R, Mattuella F, Rabello LT. Artroplastia total do joelho. Avaliação a médio prazo: dois a dez anos. Rev Bras Ortop. 2000.3;35:94-101.

11. Villardi A, Veiga LT, Mandarino M, Schott M. Artroplastia total do joelho não cimentada, sem substituição da patela: avaliação clínico-funcional. Rev Bras Ortop. 2005. 9;40:507-24.

12. Kahlenberg CA, Lyman S, Joseph AD, Chiu YF, Padgett DE. Comparison of patient-reported outcomes based on implant brand in total knee arthroplasty: a prospective cohort study. Bone Joint J. 2019 Jul;101-B(7_Supple_C):48-54.

13. Labek G, Thaler M, Janda W, Agreiter M, Stöckl B. Revision rates after total joint replacement: cumulative results from worldwide joint register datasets. $J$ Bone Joint Surg Br. 2011. 93(3):293-7. Erratum in: J Bone Joint Surg Br. 2011 Jul:93(7):998. PMID: 21357948

14. Guglielmetti LG, da Costa PP, de Paula Leite Cury R, de Oliveira VM, Severino $\mathrm{NR}$, de Camargo OP. Total knee arthroplasty with mobile tibial weight-bearing clinical evaluation after a minimum of five years of postoperative follow-up. Rev Bras Ortop. 2015. 30;50(3):290-4. 